\title{
Encouraging News from Canada's Minister of the Environment
}

Thank you for your letter of March 21 concerning publication* of my letter to you of February $22 \ldots$ Since that time further developments have taken place which I will mention to bring the information up to date, and which I hope you will also be able to pass on to your world-wide readership.

Arrangements have already been made to have the Wildlife Interpretation Centres operated largely by non-government organizations and with enhanced services to the public. I am pleased to say that these arrangements have been reached in cooperation with the Provinces. With the exception of some initial start-up funding, these centres will be operated at little or no cost to the taxpayer and with greater participation by local community groups. In addition, my provincial colleagues and I, together with various nongovernmental organizations, will be discussing the whole area of wildlife management in Canada at a colloquium later this year. We will investigate new ways of financing wildlife research and management, so that more efficient and effective ways of coordinating our efforts can be found. We will also take the opportunity to review the whole question of federal-provincial responsibilities on wildlife matters.

\section{Monitoring Toxic Chemicals}

I am very aware of the need to maintain and indeed increase our program to understand and monitor toxic chemicals. The Herring Gull [Larus argentatus] egg-monitoring project has been restored, and the analyses will be carried out at the Canada Centre for Inland Waters, Environment Canada's main centre for toxic chemicals research. These laboratories are among the most sophisticated in Canada, with the highest level of quality control.

The Herring Gull egg-monitoring project is just one component of a very large Great Lakes Surveillance and Monitoring program. Canada spends 6 million dollars annually on this program, and will increase that by $\$ 800$ thousand when the Canada-Ontario Great Lakes Water Quality Agreement is signed. The Province of Ontario spends $\$ 33$ millions on near-shore surveillance and effluent monitoring.

\section{Reducing Acidic Deposition}

You are no doubt aware of the major effort by Canada to reduce the insidious effects of acid rain on our 'total ecosystem' - including air, water, and land. The acid rain policy is based on achieving an environmental objective of [not more than] 20 kilograms of wet sulphate deposition per hectare per year-the level which lakes and rivers in Canada can tolerate without damage occurring. With provincial governments and industry, we will reduce emissions of sulphur dioxide by $50 \%$ by 1994 . We will adopt tougher motor-vehicle emission standards, effective September 1987 , to reduce emissions of nitrogen oxides from cars by $45 \%$.

We will make $\$ 150$ millions available to assist the smelting industry to install pollution controls. We have also assured that up to $\$ 25$ millions will be available to support the development of new pollution control technology. The government has confirmed that over $\$ 70$ millions will be spent to make the use of coal cleaner and more efficient. We are investigating the prospects of increased use of western low-sulphur coal in eastern Canada.

\footnotetext{
${ }^{*}$ On page 184 of our latest issue. $-\mathrm{Ed}$.
}

\section{Wildlife Habitat Canada Projects}

The acquisition of wildlife habitat by the Government of Canada through the Canadian Wildlife Service began in 1967 and has continued. In November 1984 I officially opened the office of Wildlife Habitat Canada, a new charitable organization dedicated to the improvement, enhancement, and maintenance, of wildlife environs.

A noted wildlife artist, Mr Robert Bateman, has been asked to create the first habitat stamp for distribution to the public in August. Revenues from the stamp, in addition to donations and government grants, will be used to fund cooperative projects between Wildlife Habitat Canada and other wildlife groups and agencies.

$\mathrm{Mr}$ Stewart Morrison, Chairman of Wildlife Habitat Canada, announced that the Board has approved support for ten wildlife habitat projects. The ten projects represent most regions of the country and focus on the protection of a wide diversity of plant and animal species and their habitats. Wildlife Habitat Canada will monitor wildlife habitat issues and act as a catalyst in supporting other groups and agencies, in order to help protect our important wildlife heritage.

\section{Wildlife Toxicology Fund}

One June $4 \mathrm{I}$ and Mr Monte Hummel, Executive Director of World Wildlife Fund (Canada), jointly announced the establishment of a $\$ 1$ million Wildlife Toxicology Fund for 1985-86. The new Fund will support high-quality scientific work in universities and other nongovernment research institutions in the following areas:

1. Effects of agricultural/forestry chemicals on wildlife.

2. Effects of toxic pollutants on wildlife.

3. Monitoring success of measures taken to mitigate 1 and 2.

4. Developing and implementing techniques that use wildlife as indicators of toxic chemicals in the environment.

5. Examining environmental pathways by which toxic substances may affect wildlife.

This Fund is intended to be supplementary to existing government programs. It will serve a catalytic purpose, to encourage a greater commitment to wildlife toxicology research on the part of foundations, corporations, and other levels of government.

The new Wildlife Toxicology Fund will be a matching fund, providing up to half the cost of approved research proposals. Therefore, applicants will be encouraged to find the balance of their funding from other, non-government sources. In this way it is hoped that the original \$1 million provided by Environment Canada will attract at least a matching $\$ 1$ million from corporations, foundations, and other levels of government. If successful, this Fund may be continued on an annual basis. The establishment of this Fund reflects the high priority which my Department attaches to wildlife toxicology concerns, and our commitment to good research through the Canadian Wildlife Service. It also indicates this government's new way of doing things in cooperation with the non-government and private sectors.

\section{Endangered Species}

Canada is concerned about endangered species and is a signatory of the Convention on International Trade in 


\section{Endangered Species. $\dagger$}

To ensure that endangered species in Canada receive proper attention, the Department provides a secretariat for the Committee on the Status of Endangered Wildlife in Canada. That Committee, begun in 1977, furnishes information on flora and fauna regarded, on the best scientific

$\dagger$ CITES, the Secretary-General of which happens to be a Canadian.-Ed. evidence, as at risk. I wish to thank you for your continuing interest in our work.

[Signed: Yours sincerely, etc.]

Suzanne Blais-Grenier, Minister Environment Canada

Ottawa

Ontario $\mathrm{K} 1 \mathrm{~A}$ OH3

Canada.

\section{US Pledges Support for UNEP and Observes World Environment Day}

The United Nations Environment Programme (UNEP) ended its 13 th Annual Governing Council meeting in Nairobi, Kenya, on 24 May 1985. Delegates to the "businesslike' session did not dwell on extraneous political or regional concerns but instead worked harmoniously to move the UNEP secretariat towards a carefully-thoughtout and integrated programme.

Shortly before the opening of the meeting, the US delegation received administration approval to announce the US pledge of $\$ 10$ millions towards this year's UNEP budget of about US \$35 millions. Each year, the Reagan administration has sought to cut the US contribution, which in recent years has been restored by Congress to the usual $\$ 10$ million pledge. This year's pledge was restored thanks to the efforts of environmentalists, including Sierra Club members, and congressional supporters of UNEP, in particular Representative David Obey (D-Wisconsin). Rep. Obey successfully fought administration efforts to cut this year's Fiscal Year 1985 budget by $\$ 5.4$ millions and to give these funds to the International Atomic Energy Agency.

At the Governing Council meeting, the US promoted priority action and programme focus on: the GEMS (Global Environmental Monitoring System) and the new GRID (Global Resources Information Database); regional seas; desertification; International Registry of Potentially Toxic Chemicals; and environmental law and education. The environmental law programme of UNEP, the US, and others, stressed needs to continue to work on standards relating to ozone, hazardous wastes and chemicals, land-based marine pollution, and environmental impact assessment.
On World Environment Day, June 5th - a day designated by the United Nations for people everywhere to celebrate and reaffirm their dedicatioin to preserving the environment - the North American office of UNEP honoured individual and community initiatives. Young people who have worked in the California Conservation Corps and the Katimavik (the Eskimo word for 'meeting place')-the volunteer Canadian Youth Service-as well as Joseph P. Kennedy II, the Goodyear Tire and Rubber Company, and the Mayor of Akron, Ohio, were among those who received awards from the UN Secretary-General and UNEP's Excutive director. Two Canadians were also recipients: David Suzuki, for his nature series on Canadian television, and Senator H.O. Sparrow, for soil conservation.

A special award was presented to the Academy of Science of the USSR for preserving the beauty, purity, and wildlife, of Lake Baikal, the deepest and volume-wise largest freshwater lake in the world. Another award went to the Talavaya Center, which perpetuates the genetic diversity of native southwest agricultural crops by utilizing centuries-old farming methods practiced by the Talavaya Indians. Many Sierra Club supporters from the New York metropolitan area were invited to join in the celebration.

Patricia J. Scharlin, Director Sierra Club International Earthcare Center 228 East 48th Street

New York

NY 10017, USA.

\section{Identification of Largest Known Structure in the Universe - an Assemblage of Galaxies}

Astronomers have identified the largest known structure in the universe, an assemblage of galaxies and clusters of galaxies more than one thousand million light-years in length. The largest previously-reported similar structure, called a 'filament', was an assemblage or association of galaxies about 700 million light-years long, discovered in November 1982. A light-year is the distance that light travels in a year at a speed of 186,000 miles $(297,600 \mathrm{~km})$ per second-about six trillion miles in US terminology.

The newly-discovered system of galaxies was found in the northern region of the sky by Dr Jack O. Burns, an Associate Professor of Astronomy, and David J. Batuski, a graduate student, at the University of New Mexico. The large 'filament' is in the direction of two constellations, Perseus and Pegasus, and lies beyond 200 million lightyears from Earth.

The detection and study of such superclusters of galaxie is helpful to astronomers trying to learn more about the evolution of the universe. One group holds that galaxies were formed when supercluster-sized clouds of gas fragmented and condensed. Another school holds that relatively small galaxy-size structures formed first and then clustered as gravitational forces took hold and drew them together as the universe aged.
'We feel quite strongly that our data favour the model in which the superclusters formed first and galaxies later fragmented from supercluster clouds,' Dr Burns told the NSF. 'With such a model, the universe must be dominated by some form of dark or unseen matter, such as the exotic particles predicted recently by high-energy physicists.'

Dr Burns explained that, in order for structures of this size to be formed, more gravitational force, and therefore more mass, is needed than is present in luminous matterstars and galaxies. 'Therefore,' he said, 'we must postulate the existence of a dominant component of the universe consisting of non-luminous matter.'

The New Mexico astronomers used an Intensified Image Dissector Scanner-an electronic spectrograph-on the National Optical Astronomy Observatories' 84-inches (2.1-metres) telescope on Kitt Peak in Arizona. The spectrograph allowed them to determine distances of the galaxies and, therefore, three-dimensional positions of the galaxies within the 'filament'. 'This technique allowed us to recognize, for the first time, the existence of this filament,' Dr Burns said.

RALPH KAZARIAN
National Science Foundation
1800 G Street
Washington, DC 20550, USA.

